\title{
Ulysses: the Homeric Names and Order of the Episodes
}

\section{Telemachia}

1. Telemachus

2. Nestor

3. Proteus

\section{Odyssey (The Wanderings of Ulysses)}

4. Calypso

5. Lotus Eaters

6. Hades

7. Aeolus

8. Lestrygonians

9. Scylla and Charybdis

10. Wandering Rocks

11. Sirens

12. Cyclops

13. Nausicaa

14. Oxen of the Sun

15. Circe

\section{Nostos (Homecoming)}

16. Eumaeus

17. Ithaca

18. Penelope 